\title{
Investigation of Decision Making and Thinking Styles of Volleyball Referees in Terms of Some Variables
}

\author{
Cansel Arslanoğlu ${ }^{1}$, Erol Doğan² ${ }^{2}$ Kürşat Acar ${ }^{1}$ \\ ${ }^{1}$ Sinop University, Faculty of Sport Sciences, Sinop, Turkey \\ ${ }^{2}$ Ondokuz Mayıs University, Faculty of Sport Sciences, Samsun, Turkey \\ Correspondence: Cansel Arslanoğlu, Sinop University, Faculty of Sport Sciences, Sinop, Turkey.
}

Received: July 11, 2018

doi:10.11114/jets.v6i10.3431
Online Published: July 26, 2018

URL: https://doi.org/10.11114/jets.v6i10.3431

\begin{abstract}
This study aims to examine the decision making and thinking styles of volleyball referees in terms of some variables. A total of 91 volleyball referees (51 men and 40 women) in Ankara volunteered to participate in the study. Of the participants, 56 are regional referees while 35 are national referees. The participants were applied rational-experiential thinking styles scale developed by Epstein et al (1996) and adapted into Turkish by Buluş (2000) and decision-making styles scale developed by Scott and Burce (1995) and adapted into Turkish by Taşdelen (2002). It was determined that the data obtained from the study did not show normal distribution according to Shapiro Wilk and Levene tests $(p<0.05)$, therefore, in line with the purposes of the study, the data were analyzed by Mann Whitney U test and Kruskall Wallis test, and the Steel Dwass test was applied to determine the groups from which the difference originated in multiple comparisons. The significance level was accepted as $(\mathrm{p}<0.05)$. According to research findings, decision-making styles are significant in terms of gender, age, referee category and experience (years) variables $(\mathrm{p}<0.05)$. When the scores of the "cognitive requirement and intuitive belief" subscales of the rational-experiential thinking style scale were examined, significance was determined $(\mathrm{p}<0.05)$ in terms of participants' gender, age, referee category and experience variables. Consequently, the research revealed that variables such as gender, age, referee category, and experience had an important impact on the decision-making and rational-experiential thinking styles of volleyball referees.
\end{abstract}

Keywords: Thinking styles, volleyball referee, decision making

\section{Introduction}

Every individual develops specific methods and approaches in his/her relation with the world, in his/her perception of the world, when reaching his/her ideals and solving problems. In this process, the individual draws attention to the different aspects of the truth, collects different sorts of data, organizes data in different ways, derives different judgments, reaches different decisions and applies these decisions in different ways (Buluş, 2000).

The decision is to prefer and choose the best option in the shortest time possible under the existing possibilities. Choosing is to regard one option superior to the other one. Choosing in the real sense means using one's will. In this respect, choosing is a human attribute. For, in order to be able to choose, one needs to have abilities such as not to choose, to give up, and to object (İslamoğlu, 2017). Decision-making behavior generally involves defining purposes for collecting the information for the purpose, creating options by considering and evaluating such information, and choosing the most appropriate option amongst the available ones (Güçray, 2001).

Decision-making style is the situation in which a person takes approaches, gives reactions, and takes actions during a decision-making process (Phillips et al., 1984). Therefore, the attitude of the individuals in the decision-making process and their attitude towards the problems are important. The decision-making strategy, which includes the individual's approach to the problem of decision-making and the methods to be followed while making decisions, will influence the nature of the decision (Kuzgun, 2000).

Thinking styles theory is, on the other hand, based on mental self-management theory. This theory suggests that people manage their daily activities as if they were managing a society. Everyone has different ways of thinking when dealing with the events that occur. Thinking style can vary according to the requirements of the situation. Thinking styles can be closely related to the social environment and can change depending on the culture, time and situation (Zabukovec and 
Grum, 2004). Depending on this assumption, styles can be improved or modified (Sternberg, 1997; Zhang, 2004). Besides, there is a need to support innovation in organized environments such as refereeing. For this reason, it has been reported that innovation is directly related to the empowerment of the staff (Yildirım and Karabey, 2016).

Thinking styles are the approaches and tendencies that individuals exhibit in face of various problems, events, phenomena and variables after mental processes (Sünbül, 2004). The thinking style is the information processing method that an individual develops wittingly or unwittingly in his/her relation with the world, in his/her perception of the world, when reaching his/her purposes and solving problems (Parlette and Rae, 1993). In other words, they are the processes that determine people's approaches and the way they express themselves in face of the problems and events (Sternberg and Grigorenko, 1993).

In addition to the studies in sports-related (Arslanoğlu et al, 2010), there are also studies on corporate identity conducted on different professional groups (Yıldırım, 2017). Decision-making and rational-experiential thinking styles begin when the individual perceives that there is a situation that requires making a choice. The way of perceiving incidents which vary from one person to another is influenced by personality traits as well as external environmental factors. For this reason, the same data or information is perceived and interpreted by different people in different ways. Therefore, factors affecting person's perception process (age, experience, attitudes, values, physical and social factors, culture, etc.) influence decision-making behavior and thinking styles. In this context, it is very important for the volleyball referees to make instant decisions in terms of the feature of the game. The decisions made in a very short time are closely related to the mental processes of referees. The referees who manage the mental process correctly will inevitably be successful in decision-making and thinking styles. In light of this information, the aim of our study is to determine the decision-making and thinking styles of volleyball referees and whether the decision-making and thinking styles of the referees are related to demographic variables.

\section{Method}

\subsection{Research Group}

A total of 91 volleyball referees (51 men and 40 women) who worked in Ankara within Turkish Volleyball Federation under the 2012 work program volunteered constituted the research group in the study. Of the participants, 56 are regional referees while 35 are national referees.

\subsection{Data Collection Tools}

Decision-making Styles Scale and Rational-Experiential Thinking Styles Scale were applied to the referees participating in the research.

\section{Decision-Making Styles Scale}

Decision-making style scale was developed by Scott and Bruce (1995) to measure individual differences in decision-making styles which individuals exhibit in face of the problems. The scale consists of 25 items and is scored according to a five-point Likert Scale. Scale items are measured according to "strongly disagree" (1), "disagree" (2), "neither agree nor disagree" (3), "agree" (4) and "strongly agree" (5). Decision-making style scale consists of five sub-dimensions. These dimensions can be listed as "rational", "intuitive", "dependent", "spontaneous-instant" and "avoiding" decision making styles (Scott and Bruce, 1995). Items of related sub-dimensions are included in the scale as follows:

Rational Decision-Making Style: 1, 2, 3, 4, 5.

Intuitive Decision-Making Style: 6, 7, 8, 9, 10.

Dependent Decision-Making Style: 11, 12, 13, 14, 15.

Avoiding Decision Style: 16, 17, 18, 19, 20.

Spontaneous-Instant Decision-Making Style: 21, 22, 23, 24, 25.

The scale was adapted to Turkish by (Taşdelen, 2002). Recurrent Cronbach Alpha values for each decision-making style and for the whole scale are given below:

Rational Decision-Making Style: 0.772

Intuitive Decision-Making Style: 0.915

Dependent Decision-Making Style: 0.783

Avoiding Decision-Making Style: 0.890

Spontaneous-Instant Decision-Making Style: 0.767

Value Calculated for the Entire Scale: 0.784

Rational-Experiential Thinking Styles Scale (RETSS) 
RETSS was developed by Epstein et al. (1996) to measure the individual differences in intuitive-experiential and analytical-rational thinking styles that people use in information processing (Epstein et al., 1996). The scale, adapted into Turkish by Buluş (2000), is theoretically based on Cognitive-Experiential Self Theory (Buluş, 2000). According to the theory, people use two types of information processing (rational and experiential) systems that are different from each other but interact with each other and function in different processes. (RETSS) consists of 31 items and two subscales. One of these measures rational thinking. The short need for cognition scale was prepared with 19 items taken from the original Need for Cognition Scale (45 items) developed by Cacioppa and Petty (1982). This scale, like the original one, measures the extent to which individuals like, participate in or dislike and avoid cognitive activities. The other is the 12-item Faith in Intuition subscale, which measures the extent to which individuals rely on their emotions and first impressions in information processing and taking actions. The scale items are answered on a 5-point scale ranging from "completely wrong" to "completely true". 1st, 2nd, 4th, 5th, 6th, 7th, 9th, 10th, 11th, 13th, 15th, 16th, 18th and 19th items of the need for cognition subscale are scored reversely. Since all the items of the faith in intuition subscale are expressed positively, the scoring is performed in the form of completely wrong (1), partially wrong (2), neutral (3), partially true (4), completely true (5). The need for cognition subscale was defined as analytical-rational thinking style, whereas the faith in intuition subscale was defined as intuitive-experiential thinking style (Cacioppa and Petty, 1982). The recurrent Cronbach Alpha values for the subscales of the scale and calculated for the entire scale are given below:

Need for cognition: 0.763

Faith in intuition: 0.847

Value Calculated for the Entire Scale: 0.727

\subsection{Analysis of Data}

It was determined that the data obtained from the study did not show normal distribution according to Shapiro Wilk and Levene tests $(\mathrm{p}<0,05)$, therefore, in line with the purposes of the study, the data were analyzed by Mann Whitney U test and Kruskall Wallis test, and the Steel Dwass test was applied to determine the groups from which the difference originated in multiple comparisons. The significance level was accepted as $(\mathrm{p}<0.05)$ in the analysis of the data.

\section{Results}

Findings obtained as a result of the research are presented in tables below.

Table 1. Decision-making styles of participants according to gender

\begin{tabular}{|c|c|c|c|c|c|c|c|}
\hline Sub-dimensions & Gender & $\mathrm{N}$ & Median & IQR & Minimum & Maximum & P-value \\
\hline \multirow{2}{*}{ Rational } & Male & 51 & 21.00 & 5.00 & 15.00 & 25.00 & \multirow{2}{*}{0.888} \\
\hline & Female & 40 & 21.00 & 2.75 & 9.00 & 15.00 & \\
\hline \multirow{2}{*}{ Intuitive } & Male & 51 & 20.00 & 12.00 & 5.00 & 25.00 & \multirow{2}{*}{0.244} \\
\hline & Female & 40 & 18.50 & 4.00 & 10.00 & 23.00 & \\
\hline \multirow{2}{*}{ Dependent } & Male & 51 & 14.00 & 11.00 & 9.00 & 24.00 & \multirow{2}{*}{0.920} \\
\hline & Female & 40 & 13.00 & 3.00 & 10.00 & 18.00 & \\
\hline \multirow{2}{*}{ Avoiding } & Male & 51 & 13.00 & 7.00 & 5.00 & 25.00 & \multirow{2}{*}{$* 0.006$} \\
\hline & Female & 40 & 9.00 & 8.75 & 5.00 & 18.00 & \\
\hline Spontaneous & Male & 51 & 17.00 & 5.00 & 5.00 & 23.00 & \multirow{2}{*}{$* 0.013$} \\
\hline Instant & Female & 40 & 16.00 & 5.75 & 5.00 & 21.00 & \\
\hline
\end{tabular}

When we look at Table 1, "rational, intuitive and dependent decision making" sub-dimensions of decision-making styles are not significant $(p>0.05)$ according to gender variable. However, a significance was determined in "avoiding and spontaneous instant" sub-dimensions $(\mathrm{p}<0.05)$.

Table 2. Decision-making styles of participants according to referee category

\begin{tabular}{|c|c|c|c|c|c|c|c|}
\hline Sub-dimensions & Referee category & $\mathrm{N}$ & Median & IQR & Minimum & Maximum & P-value \\
\hline \multirow{2}{*}{ Rational } & Regional & 56 & 21.00 & 5.00 & 9.00 & 25.00 & \multirow{2}{*}{0.895} \\
\hline & National & 35 & 21.00 & 6.00 & 15.00 & 25.00 & \\
\hline \multirow{2}{*}{ Intuitive } & Regional & 56 & 18.50 & 9.75 & 5.00 & 23.00 & \multirow{2}{*}{$* 0.005$} \\
\hline & National & 35 & 20.00 & 4.00 & 5.00 & 25.00 & \\
\hline \multirow{2}{*}{ Dependent } & Regional & 56 & 13.00 & 3.00 & 9.00 & 24.00 & \multirow{2}{*}{$* 0.032$} \\
\hline & National & 35 & 15.00 & 5.00 & 9.00 & 24.00 & \\
\hline \multirow{2}{*}{ Avoiding } & Regional & 56 & 11.50 & 9.00 & 5.00 & 25.00 & \multirow{2}{*}{0.075} \\
\hline & National & 35 & 10.00 & 7.00 & 6.00 & 22.00 & \\
\hline Spontaneous & Regional & 56 & 17.00 & 4.75 & 5.00 & 23.00 & \multirow{2}{*}{0.475} \\
\hline Instant & National & 35 & 16.00 & 4.00 & 9.00 & 21.00 & \\
\hline
\end{tabular}


When we look at Table 2, "intuitive and dependent decision making" sub-dimensions show difference according to referee category ( $\mathrm{p}<0.05)$. "Rational, avoiding and spontaneous instant decision making" sub-dimensions do not show the difference ( $\mathrm{p}>0.05)$.

Table 3. Decision-making styles of participants according to age

\begin{tabular}{|c|c|c|c|c|c|c|}
\hline Sub-dimensions & Age & $\mathrm{N}$ & Median & $\mathrm{x}^{2}$ & P-value & Difference \\
\hline \multirow{4}{*}{ Rational } & $20-23$ & 42 & 21.00 & \multirow{4}{*}{12.587} & \multirow{4}{*}{$* 0.006$} & \multirow{4}{*}{$\begin{array}{r}20-23-24-27 \\
28-31\end{array}$} \\
\hline & $24-27$ & 21 & 18.00 & & & \\
\hline & $28-31$ & 8 & 22.50 & & & \\
\hline & over 32 & 20 & 21.00 & & & \\
\hline \multirow{4}{*}{ Intuitive } & $20-23$ & 42 & 18.00 & \multirow{4}{*}{17.349} & \multirow{4}{*}{$* 0.001$} & \multirow{4}{*}{$\begin{array}{l}20-23 \text { - over } 32 \\
24-27 \text { - over } 32\end{array}$} \\
\hline & $24-27$ & 21 & 20.00 & & & \\
\hline & $28-31$ & 8 & 19.00 & & & \\
\hline & over 32 & 20 & 21.00 & & & \\
\hline \multirow{4}{*}{ Dependent } & $20-23$ & 42 & 13.00 & \multirow{4}{*}{0.725} & \multirow{4}{*}{0.862} & \multirow{4}{*}{ - } \\
\hline & $24-27$ & 21 & 13.00 & & & \\
\hline & $28-31$ & 8 & 15.00 & & & \\
\hline & over 32 & 20 & 14.00 & & & \\
\hline \multirow{4}{*}{ Avoiding } & $20-23$ & 42 & 10.00 & \multirow{4}{*}{10.603} & \multirow{4}{*}{$* 0.014$} & \multirow{4}{*}{$\begin{array}{l}24-27 \text { - over } 32 \\
28-31 \text { - over } 32\end{array}$} \\
\hline & $24-27$ & 21 & 12.00 & & & \\
\hline & $28-31$ & 8 & 13.50 & & & \\
\hline & over 32 & 20 & 10.00 & & & \\
\hline \multirow{4}{*}{ Spontaneous Instant } & $20-23$ & 42 & 15.00 & \multirow{4}{*}{14.383} & \multirow{4}{*}{$* 0.002$} & \multirow{4}{*}{$20-23-28-31$} \\
\hline & $24-27$ & 21 & 18.00 & & & \\
\hline & $28-31$ & 8 & 18.50 & & & \\
\hline & over 32 & 20 & 15.00 & & & \\
\hline
\end{tabular}

When we look at Table 3, "rational, intuitive, avoiding and spontaneous instant" decision-making styles show significance according to age variable $(\mathrm{p}<0.05)$. That is, participants' decision-making mechanisms evolve in parallel with age.

Table 4. Decision-making styles of participants according to experience (years)

\begin{tabular}{|c|c|c|c|c|c|c|}
\hline Sub-dimensions & Experience (years) & $\mathrm{N}$ & Median & $\mathrm{x}^{2}$ & P-value & Difference \\
\hline \multirow{5}{*}{ Rational } & $1-3$ & 38 & 21.00 & \multirow{5}{*}{9.868} & \multirow{5}{*}{$* 0.043$} & \multirow{5}{*}{$\begin{array}{l}1-3-10-12 \\
4-6-10-12 \\
7-9-10-12\end{array}$} \\
\hline & $4-6$ & 25 & 21.00 & & & \\
\hline & $7-9$ & 12 & 19.00 & & & \\
\hline & $10-12$ & 8 & 23.00 & & & \\
\hline & 13 and over & 8 & 20.50 & & & \\
\hline \multirow{5}{*}{ Intuitive } & $1-3$ & 38 & 16.00 & \multirow{5}{*}{24.954} & \multirow{5}{*}{$* 0.000$} & \multirow{5}{*}{$\begin{array}{l}1-3-4-6 \\
7-9 \\
13 \text { and over }\end{array}$} \\
\hline & $4-6$ & 25 & 20.00 & & & \\
\hline & $7-9$ & 12 & 20.00 & & & \\
\hline & $10-12$ & 8 & 19.50 & & & \\
\hline & 13 and over & 8 & 23.00 & & & \\
\hline \multirow{5}{*}{ Dependent } & $1-3$ & 38 & 14.00 & \multirow{5}{*}{14.954} & \multirow{5}{*}{$* 0.005$} & \multirow{5}{*}{$\begin{array}{l}4-6-10-12 \\
7-9-10-12\end{array}$} \\
\hline & $4-6$ & 25 & 13.00 & & & \\
\hline & $7-9$ & 12 & 13.00 & & & \\
\hline & $10-12$ & 8 & 16.50 & & & \\
\hline & 13 and over & 8 & 17.50 & & & \\
\hline \multirow{5}{*}{ Avoiding } & $1-3$ & 38 & 10.50 & \multirow{5}{*}{13.845} & \multirow{5}{*}{$* 0.008$} & \multirow{5}{*}{$\begin{array}{l}1-3-7-9 \\
4-6-7-9 \\
7-9-10-12\end{array}$} \\
\hline & $4-6$ & 25 & 15.00 & & & \\
\hline & $7-9$ & 12 & 9.00 & & & \\
\hline & $10-12$ & 8 & 14.50 & & & \\
\hline & 13 and over & 8 & 9.50 & & & \\
\hline \multirow{5}{*}{ Spontaneous Instant } & $1-3$ & 38 & 16.00 & \multirow{5}{*}{9.544} & \multirow{5}{*}{$* 0.049$} & \multirow{5}{*}{$\begin{array}{l}1-3-10-12 \\
4-6-10-12\end{array}$} \\
\hline & $4-6$ & 25 & 16.00 & & & \\
\hline & $7-9$ & 12 & 15.00 & & & \\
\hline & $10-12$ & 8 & 19.50 & & & \\
\hline & 13 and over & 8 & 17.00 & & & \\
\hline
\end{tabular}


When we look at Table 4, "rational, intuitive, dependent, avoiding, spontaneous instant" sub-dimensions show significance according to experience $(\mathrm{p}<0.05)$. In summary, as the participants' professional experience increases, their ability to make decisions also develops positively.

Table 5. Rational-experiential thinking styles of participants according to gender variable

\begin{tabular}{lcc|c|c|c|c|cc}
\hline \multicolumn{2}{l}{ Sub-dimensions } & Gender & $\mathrm{N}$ & \multicolumn{1}{l}{ Median } & IQR & Minimum & Maximum & \multirow{2}{*}{ P-value } \\
\hline \multirow{2}{*}{$\begin{array}{l}\text { Need for } \\
\text { cognition }\end{array}$} & Male & 51 & 59.00 & 9.00 & 47.00 & 70.00 & \multirow{2}{*}{$* 0.001$} \\
\cline { 2 - 9 } & Female & 40 & 66.00 & 8.00 & 47.00 & 81.00 & \\
\hline \multirow{2}{*}{ Faith in intuition } & Male & 51 & 49.00 & 9.00 & 28.00 & 55.00 & \multirow{2}{*}{0.424} \\
\cline { 2 - 9 } & Female & 40 & 46.00 & 12.00 & 28.00 & 58.00 & \\
\hline
\end{tabular}

According to Table 5, need for cognition sub-dimension of rational-experiential thinking styles differs according to gender variable $(\mathrm{p}<0,05)$. There was no difference in the faith in intuition sub-dimension $(\mathrm{p}<0.05)$.

Table 6. Rational-experiential thinking styles of participants according to referee category

\begin{tabular}{|c|c|c|c|c|c|c|c|}
\hline Sub-dimensions & Referee category & $\mathrm{N}$ & Median & IQR & Minimum & Maximum & P-value \\
\hline \multirow{2}{*}{$\begin{array}{l}\text { Need for } \\
\text { cognition }\end{array}$} & Regional & 56 & 61.00 & 11.00 & 47.00 & 81.00 & \multirow{2}{*}{0.358} \\
\hline & National & 35 & 62.00 & 11.00 & 50.00 & 81.00 & \\
\hline \multirow{2}{*}{ Faith in intuition } & Regional & 56 & 44.00 & 10.75 & 28.00 & 52.00 & \multirow{2}{*}{$* 0.001$} \\
\hline & National & 35 & 52.00 & 6.00 & 31.00 & 58.00 & \\
\hline
\end{tabular}

When we look at Table 6, the "faith in intuition" sub-dimension of rational-experiential thinking styles shows significance in favor of national referees $(p<0.05)$. There was no significant difference in the need for cognition sub-dimension ( $\mathrm{p}>0.05$ ).

Table 7. Rational-experiential thinking styles of participants according to age variable

\begin{tabular}{|c|c|c|c|c|c|c|}
\hline Sub-dimensions & Age & $\mathrm{N}$ & Median & $x^{2}$ & P-value & Difference \\
\hline \multirow{4}{*}{ Need for cognition } & $20-23$ & 42 & 65.00 & \multirow{4}{*}{13.52} & \multirow{4}{*}{$* 0.004$} & \multirow{4}{*}{$\begin{array}{l}20-23-28-31 \\
24-27-28-31\end{array}$} \\
\hline & $24-27$ & 21 & 61.00 & & & \\
\hline & $28-31$ & 8 & 53.50 & & & \\
\hline & over 32 & 20 & 62.00 & & & \\
\hline \multirow{4}{*}{ Faith in intuition } & $20-23$ & 42 & 44.00 & \multirow{4}{*}{28.21} & \multirow{4}{*}{$* 0.001$} & \multirow{4}{*}{$\begin{array}{l}20-23-24-27 \\
28-31 \\
32 \text { and over }\end{array}$} \\
\hline & $24-27$ & 21 & 44.00 & & & \\
\hline & $28-31$ & 8 & 48.50 & & & \\
\hline & over 32 & 20 & 53.00 & & & \\
\hline
\end{tabular}

$* \bar{p}<0.05$

When we look at Table 7, "need for cognition and faith in intuition" sub-dimensions of rational-experiential thinking styles are significant according to age variable $(\mathrm{p}<0.05)$. Therefore, it can be said that with the advancement of age, rational-experiential thinking styles of participants also improved.

Table 8. Rational-experiential thinking styles of participants according to experience

\begin{tabular}{|c|c|c|c|c|c|c|}
\hline $\begin{array}{l}\text { Sub-dimensio } \\
\text { ns }\end{array}$ & $\begin{array}{l}\text { Experience } \\
\text { (years) }\end{array}$ & $\mathrm{N}$ & Median & $\mathrm{x}^{2}$ & P-value & Difference \\
\hline \multirow{5}{*}{$\begin{array}{l}\text { Need } \\
\text { cognition }\end{array}$} & $1-3$ & 38 & 63.00 & \multirow{5}{*}{5.273} & \multirow{5}{*}{0.260} & \multirow{5}{*}{ - } \\
\hline & $4-6$ & 25 & 61.00 & & & \\
\hline & $7-9$ & 12 & 64.00 & & & \\
\hline & $10-12$ & 8 & 58.00 & & & \\
\hline & 13 and over & 8 & 58.00 & & & \\
\hline \multirow{5}{*}{$\begin{array}{l}\text { Faith } \\
\text { intuition }\end{array}$} & $1-3$ & 38 & 46.50 & \multirow{5}{*}{45.931} & \multirow{5}{*}{$* 0.000$} & \multirow{5}{*}{$\begin{array}{c}1-3-7-9 \\
10-12 \\
13 \text { and } \\
\text { over }\end{array}$} \\
\hline & $4-6$ & 25 & 44.00 & & & \\
\hline & $7-9$ & 12 & 55.00 & & & \\
\hline & $10-12$ & 8 & 50.00 & & & \\
\hline & 13 and over & 8 & 51.00 & & & \\
\hline
\end{tabular}

When we look at Table 8, there was a difference in the "faith in intuition" sub-dimension of rational-experiential thinking styles according to experience. As can be seen from the table, rational-experiential thinking styles also evolve with the advancement of refereeing experience. 


\section{Discussion}

The findings obtained from this study on volleyball referees' decision-making and rational-experiential thinking styles have been discussed and interpreted in this section. The findings of this study were supported by the findings obtained as a result of the literature review.

When the decision-making styles of the participants are examined according to the gender variable, a significance was determined in the "avoiding and spontaneous instant" subscales. There was no difference in the rational, intuitive, cognitive sub-dimensions (Table 1). In a similar study, Tekin et al. (2009) found no significant difference in terms of gender variable. In another research on university students, Yüceloğlu et al (2016) did not find a difference between gender variable and decision-making behavior. However, these findings are not similar to the findings of the studies of Haniffa and Ahmed (2008), Dilmaç and Bozgeyikli (2009) and Salo and Allwood (2011). These studies found that male and female participants adopted different decision-making styles. In summary, when the literature is reviewed, it can be seen that decision-making styles do not differ between men and women. When thinking styles are analyzed according to gender variable, "need for cognition" sub-dimension is significant. No significance was found in the "faith in intuition" sub-dimension (Table 5). The studies of Buluş (2000), Zhang (1999), Waters et al (1990) and Duru (2002) found no statistically significant difference between gender and thinking styles. However, in their study on ski coaches, Özmutlu et al (2008) found differences between men and women. The fact that participants' thinking styles showed a difference in favor of women in the "need for cognition" sub-dimension in our study is thought to be related to the difference the research groups of this study and other studies.

When participants' decision-making styles are examined according to the referee category, another variable in our study, the "intuitive and dependent" sub-dimension is significant in favor of "National" referees (Table 2). In a similar study, Uzunoğlu et al. (2009) stated that referees' decision-making behaviors differ according to classifications. Therefore, these findings indicate that the professional experience of referees is influential in their decision-making mechanisms. Hormones are also thought to be influential on the stress-dependent decision-making mechanism (Kayacan et al., 2017). In this context, the fact that national referees have better decision-making mechanisms compared to regional referees is related to stress management in parallel with their professional experience. When the participants' thinking styles are evaluated according to the referee category, the "faith in intuition" sub-dimension is significant in favor of national referees (Table 6).

When the decision-making styles of the participants are examined in terms of the age variable considered to be an important variable in our research, it can be seen that "rational, intuitive, avoiding and spontaneous instant" decision-making styles are significant (Table 3). In their study examining the Decision-Making Styles of Turkish Football Referees by Classifications and Some Variables, Uzunoğlu et al. (2009) found that the avoidant scores of 18-25 age referees were higher than the avoidant scores of 26-30 age and 36-40 age referees (Özmutlu et al., 2008). Therefore, it is stated that the young referees tend to escape from the decision-making responsibility in the decision-making phase when compared to the referees of older age groups. In summary, decision-making mechanisms develop positively as age increases. Our study also supports this finding. When we look at the age variable in terms of thinking styles, "need for cognition and faith in intuition" sub-dimensions are significant according to age variable (Table 7). In a similar study, İslamoğlu et al. (2017) found significance in the "faith in intuition" sub-dimension of thinking styles. Zhang and Sternberg (2002) reported differences between age and thought styles. These findings are parallel to our findings. In conclusion, we can say that age has an important influence on thinking styles.

When we examine the experience, another variable of our study, in terms of decision-making styles, "rational, intuitive, dependent, avoiding, spontaneous instant" sub-dimensions are significant (Table 4). Yalçın et al. (2016) observed a steady increase in the level of careful decision-making as the refereeing experience increased. This result also reveals that experience is important for decision making in the refereeing experience variable, as in the age variable. When we look at different studies, in the study on the decision making levels of physical education and other branch teachers, Kirgil (2015) found no statistically significant result between the experience and decision making sub-dimensions. When we look at the refereeing experience in terms of thinking styles, there was a difference in the "faith in intuition" sub-dimension according to the experience (Table 8). Intuitive thinking style is a system that functions affected by automatic, consciousness-based, connotation-based, holistic, not verbal in nature and instant emotions (Epstein et al., 1996). In this context, it can be seen that the thinking styles of referees improve in parallel with their experience.

As a result, when the findings of the variables of our study are analyzed, it is seen that the gender, age, experience and referee category have a significant influence on decision-making and thinking styles of volleyball referees. The mental processes of the referees are particularly influential on the results of volleyball matches. In this context, it is important that volleyball referees' thinking styles that are effective in decision-making and reasoning skills should be revealed and their mental structures should be developed. 


\section{References}

Arslanoğlu, E., Tekin, M., Arslanoğlu, C., \& Özmutlu, İ. (2010). Investigation of anxiety levels and basic psychological needs of volleyball referee accoarding to different variables (Sample of Ankara). International Human Science, $7(2), 985-995$.

Buluş, M. (2000). Attributional complexity, thinking styles and preference for cognitive consistency in relation to some psychosocial characteristics and academic achievement in student teachers. Dokuz Eylül University, Institute of Educational Sciences, Doctoral Thesis, İzmir.

Cacioppa, J., \& Petty, R. (1982). Social psychophysiology. New York: Guilford.

Dilmaç, B., \& Bozgeyikli, H. (2009). A Research On Subjective Well-Being And Decision Making Of Teacher Candidates. Erzincan University Journal of Education Faculty, 11(1), 171-187.

Duru, E. (2002). The Relationship between helping behavior tendency, empathy and thinking styles of prospective teachers in term of person condition trend and investigation of these variables according to some psychosocial variables, Dokuz Eylül University, Institute of Educational Sciences, Doctoral Thesis, İzmir.

Epstein, S., Rosemary, P., Denes, V. R., \& Harriet, H. (1996). Individual differences in intuitive experiental and analytical rational thinking styles. Journal of Personlity and Social Psychology, 63(4), 553-554.

Güçray, S. (2001). Ergenlerde karar verme davranışlarının öz-saygı ve problem çözme becerileri algısı ile ilişkisi. Çukurova Üniversitesi Sosyal Bilimler Dergisi, 8(8),106-121.

Haniffa, M. B. M., \& Ahmed, E. M. (2008). Gender differences in decision-making styles of Malasian managers. European Journal of Scientific Research, 19(3), 405-415.

İslamoğlu, İ., Atan, T., \& Ünver, Ş. (2017). Analysis of wrestlers' thinking styles. European Journal of Physical Education and Sport Science, 3(12), 499-507.

Kayacan, Y., Mor, A., Özgocer, Y., Uçar, C., \& Yıldız, S. (2017). Psychophysiological stress regulation in football athletes during competition. Medicina dello Sport, 70(3), 333-43.

Kirgil, F. (2015). The examine the decision-making and assertiveness levels of physical education teachers and other branch teachers in terms of some variables. Firat University Institute of Health Sciences, Master Thesis, Elazığ.

Kuzgun, Y. (2000). Meslek danışmanlığı. Nobel Yayın Dağıtım, Ankara.

Özmutlu, İ., Tekin, M., \& Arslanoğlu, E. (2008). Kayak antrenörlerinin çeşitli değişkenlere göre karar verme ve düşünme stillerinin incelenmesi. I. World Forensic Sciences and Sport Congress, 27-30 November, Ankara.

Parlette, N., \& Rae, R. (1993). Thinking about thinking (thinking styles of people). Association management, 45(3), 70-74.

Phillips, S. D., Pazienza, N. J., \& Ferrin, H. H. (1984). Decision-making styles and problem-solving appraisal. Journal of Counseling Psychology, 31(4), 497-502. https://doi.org/10.1037/0022-0167.31.4.497

Salo, I., \& Allwood, C. M. (2011). Decision-making styles, stres and gender among investigators. An International Journal of Police Strategies \& Management, 34(1), 97-119. https://doi.org/10.1108/13639511111106632

Scott, S. G., \& Bruce, R. A. (1995). Decision making style, the development and of a new measure. Educational and Psychological Measurement, 55(5), 818-831. https://doi.org/10.1177/0013164495055005017

Sternberg, R. J. (1997). Thinking styles. Combridge University Press. New York. https://doi.org/10.1017/CBO9780511584152

Sternberg, R. J., \& Grigorenko, E. L. (1993). Thinking styles and the gifted, Roeper Review, 16, $122-131$. https://doi.org/10.1080/02783199309553555

Sünbül, A. M. (2004). The Validity Reliability of the Thinking Styles Scale.Education and Science, 29(132), $25-42$.

Taşdelen, A. (2002). Decision making sytes of student teachers in relation to different psychosocial characteristics. Dokuz Eylül University, Institute of Educational Sciences, Doctoral Thesis, İzmir.

Tekin, M., Özmutlu, İ., \& Erhan, S. E. (2009). Investigation the Thinking and Decision Making Styles of the Student That Participate Special Ability Examamination. Atatürk University Journal of Physical Education and Sport Sciences, 11(3), 43-56.

Uzunoğlu, Ö. U., Şahin, M., \& Fişekçioğlu, İ. B. (2009), Investigation Styles of Decision Making of Turkish Football Referees According to Their Classifications and Some Variables. Selçuk University, Selçuk University Journal of Physical Education and Sport Science, 11(1), 32-36. 
Waters, L. K., \& Zakrajsek, T. (1990). Correlates of need for cognition total and subscale scores. Educational and Psychological Measurement, 50(1), 211-217. https://doi.org/10.1177/0013164490501026

Yalçın, İ., Soyer, F., Ramazanoğlu, F., \& Aksu, A. (2016). Investigation of variations in terms of decision making and trait anxiety level of football referees. Journal of Human Sciences, 13(3), 5681-5692. https://doi.org/10.14687/jhs.v13i3.4280

Yıldırım, F. (2017). The Effects of Corporate Identity on Job Satisfaction. Kirklareli University Journal of the Faculty of Economics and Administrative Sciences, 6(4), 47-54.

Yıldırım, F., \& Karabey, C. N. (2016). Moderating Role of Empowerment in the Effect of Organizational Culture on Innovation. Gazi University Journal of Faculty of Economics and Administrative Sciences, 18(2), 426-453.

Yüceloğlu, D. Ö., Bayram, L., Derebaşı, D. G., Bostancı, Ö., \& Kabadayı, M. (2016). Examining Decision Making Strategies of University Students in Terms of Some Demographic Variables. Gaziantep University Journal of Sport Science, 1(2), 1-12.

Zabukovec, Z., \& Grum, D. K. (2004). Relationship between student thinking styles and social skills. Psychology Science, 2004(41), 156-166.

Zhang, L. F. (1999). Further Cross-cultural validation of the mental self-government. The Journal of psychology, 133(1), 165-181. https://doi.org/10.1080/00223989909599731

Zhang, L. F. (2004). Thinking Styles: University students' preferred teaching styles and their conceptions of effective teachers. The Journal of Psychology, 138(3), 233-252. https://doi.org/10.3200/JRLP.138.3.233-252

Zhang, L. F., \& Sternberg, R. J. (2002). Thinking styles and teachers' characteristics. International Journal of Psychology, 37(1), 3-12. https://doi.org/10.1080/00207590143000171

\section{Copyrights}

Copyright for this article is retained by the author(s), with first publication rights granted to the journal.

This is an open-access article distributed under the terms and conditions of the Creative Commons Attribution license which permits unrestricted use, distribution, and reproduction in any medium, provided the original work is properly cited. 